\title{
A CONSTITUIÇÃO POLÍTICA DO PATRIMÔNIO HISTÓRICO CULTURAL BRASILEIRO E A BUSCA DA FORMATAÇÃO DE UMA IDENTIDADE NACIONAL
}

\section{The Political Constitution of Brazilian Cultural Historical Heritage and the Formation of a National Identity}

\author{
Rahyan de Carvalho Alves ${ }^{1}$ http://orcid.org/0000-0001-7225-5959 \\ José Antônio Souza de Deus ${ }^{2}$ https://orcid.org/0000-0002-1737-4960
}

\footnotetext{
${ }^{1}$ Doutorando em Geografia pelo Instituto de Geociências da Universidade Federal de Minas Gerais. Professor da Universidade Estadual de Montes Claros e integrante do Grupo GECES. E-mail: rahyancarvalho@yahoo.com.br

2 Professor Associado do Instituto de Geociências da Universidade Federal de Minas Gerais (IGC/UFMG). Coordenador do GECES - Grupo de Estudos Culturais e Etnogeográficos (vinculado ao Laboratório de Geografia Agrária e Agricultura Familiar do Departamento de Geografia - IGC/ UFMG) e do Núcleo TERRA \& SOCIEDADE - Núcleo de Estudos em Geografia Agrária, Agricultura Familiar e Cultura Camponesa (CNPq). E-mail: jantoniodeus@uol.com.br
}

\begin{abstract}
Resumo
O referente trabalho tem como objetivo destacar a constituição política do patrimônio histórico cultural brasileiro e a busca do governo em referências que pudessem representar a identidade nacional. Dessa forma o trabalho encontra-se estruturado em dois momentos: primeiramente destacando a constituição do patrimônio histórico brasileiro e, em seguida, as nuances da compreensão dos elementos que representam a identidade do povo brasileiro e seus signos. Adotamos como procedimento metodológico para operacionalização da investigação o retrabalhamento bibliográfico a partir dos seguintes recortes temáticos que dialogam entre si, a saber: Patrimônio Histórico, Identidade, Estado.
\end{abstract}

Palavras-chave: Patrimônio; Identidade; Estado.

\begin{abstract}
The purpose of this work is to highlight the political constitution of the Brazilian cultural historical heritage and the government's search for references that could represent the national identity. In this way the work is structured in two moments: first highlighting the constitution of the Brazilian historical heritage and then the nuances of understanding the elements that represent the identity of the Brazilian people and their signs. We adopt as methodological procedures for the operationalization of the investigation the bibliographic reworking from the following thematic clippings that dialogue among themselves, namely: Historical Heritage, Identity, State.
\end{abstract}

Keywords: Patrimony; Identity; State. 
A constituição política do Patrimônio Histórico Cultural brasileiro e a busca da formatação de uma identidade nacional

Rahyan de Carvalho Alves; José Antônio Souza de Deus

\section{Introdução}

Quando nos remetemos ao patrimônio histórico como referência cultural, pode-se refletir, conforme afirma Londres (2000), que esses elementos simbólicos de que nos são apropriados, pressupõem inúmeros sentidos culturais e políticos. Essa situação nos leva aos seguintes questionamentos: "Mas essas referências partem de quem (?), de que sujeitos?"

Se pensar do ponto de vista político, os bens culturais não valem por si mesmos, não têm um valor social pronto, pois são feitos e representados, adotados através de determinados parâmetros. Nesse sentido, Londres (2000, p.12) destaca que:

O valor lhes é sempre atribuído por sujeitos particulares e em função de determinados critérios e interesses historicamente condicionados. Levada às últimas consequências, essa perspectiva afirma a relatividade de qualquer processo de atribuição de valor - seja valor histórico, artístico, nacional, etc. - a bens, e põe em questão os critérios até então adotados para a constituição de "patrimônios culturais", legitimados por disciplinas como a história, a história da arte, a arqueologia, a etnografia, etc. [...].

Dessa forma, o referente trabalho busca apresentar uma leitura crítica sobre qual o significado e o que significa o patrimônio histórico no país, tendo como objetivo central do da pesquisa destacar a constituição política do patrimônio histórico cultural brasileiro e a busca do governo em referências que pudessem representar e "cristalizar" a identidade nacional. O referente trabalho está estruturado em dois momentos: primeiramente destacando a constituição do patrimônio histórico brasileiro e, em seguida, as nuances da compreensão dos elementos que representam a identidade do povo brasileiro e seus signos.

Adotamos como procedimento metodológico para operacionalização da investigação o retrabalhamento bibliográfico a partir dos seguintes recortes temáticos que dialogam entre si, a saber: Patrimônio Histórico, Identidade, Estado. E destacamos que este é um trabalho em andamento do Grupo de estudos GECES e do Núcleo Terra e Sociedade do Programa de Pósgraduação em Geografia da Universidade Federal de Minas Gerais.

\section{A constituição do Patrimônio Histórico Cultural no Brasil}

O Brasil tem o marco inicial de uma preocupação em preservar objetos, pertences, heranças, retratos de conquistas históricas que contam a história do país, no museu Real, em 06 de junho de 1818 (atualmente conhecido como Museu Nacional), construído sob o mando de Dom João VI (1767-1826), que acabaria reforçando como instrumentos da constituição da nacionalidade brasileira quando, em 1838, fora instituído o Instituto Histórico e Geográfico 


\section{A constituição política do Patrimônio Histórico Cultural brasileiro e a busca da formatação de uma identidade nacional}

Rahyan de Carvalho Alves; José Antônio Souza de Deus

Brasileiro e o Arquivo Nacional, responsáveis, respectivamente, pela criação da História e manutenção da memória histórica (RODRIGUES, 2002; JULIÃO, 2009).

Mas o nascimento de um processo mais rico e denso no que se refere à construção de uma referência histórica nacional, enquanto Patrimônio brasileiro inicia-se por meio de dois momentos políticos os quais são assinalados por Nuñes (2011): (i) a referência cultural do movimento modernista e (ii) a instauração do Estado Novo no país, cujos acontecimentos promoveram um movimento cultural renovador no Estado, fomentando aí, o processo de constituição do Patrimônio histórico cultural.

Vale ressaltar que a saga da valorização do patrimônio brasileiro se legitima com os intelectuais modernistas oriundos do movimento denominado "Semana da Arte Moderna", realizada no município de São Paulo, no ano de 1922, quando os artistas e políticos envolvidos localizaram nos feitos do período colonial (1530-1822) as nossas raízes socioculturais, fomentando assim o início da busca de uma identidade nacional que se queria incentivar naquele momento (SIMÃO, 2001).

A busca por materiais que pudessem remeter à história do nosso país, em termos da construção de elementos e signos, era uma questão que extrapolava a exposição de materiais nos museus, mas o que interessava naquele momento era consolidar marcas, marcos e pontos históricos em "nossa terra", para que o povo pudesse sentir-se ligado ao seu lugar, buscando referências e características da nação. E o passado era, para os modernistas, uma das bases para a solidificação de elementos-memoriais que pudessem mostrar/demonstrar ao povo o sentido de ser brasileiro (RODRIGUES, 2002; NUÑES, 2011).

Para alguns modernistas, marginalizar o passado brasileiro seria um equívoco colossal. Não podíamos anular a vida passada e começar uma nova etapa histórica sem valorizar os feitos pretéritos. Ativar a relação de pertencimento era necessário, para que assim, pudéssemos reconhecer a nossa história e formar uma unidade cultural.

A partir de 1924, certa corrente do movimento modernista passa a considerar que o passado, o nacionalismo e a "brasilidade" devem fazer parte do processo de renovação artística, da construção simbólica que afirmava que o povo brasileiro, e o Brasil, só se tornariam modernos se fossem nacionais. Esses intelectuais passaram a

\footnotetext{
${ }^{3}$ Movimento artístico conhecido como "A Semana de Arte Moderna ou Semana de 22" que representou uma nova linguagem no mundo das artes no país; movido pela insatisfação da forma de concepção da cultura ali vigente, a qual era submetida a modelos importados. O movimento buscava a afirmação de uma arte verdadeiramente brasileira, representando a busca da experimentação, da liberdade e da "ruptura com o passado", sem de fato marginalizá-lo, mas pelo contrário, valorizando as suas marcas históricas. Movimento ocorrido no teatro municipal de São Paulo, entre os dias 13 a 17 de fevereiro de 1922, participando nomes consagrados da arte, tais como os escritores: Mário Raul Morais de Andrade (1893-1945), José Oswald de Souza Andrade (1890-1954) e Plínio Salgado (1895-1975); os artistas plásticos: Anita Catarina Malfatti (1889-1964) e Emiliano Augusto Cavalcanti de Albuquerque e Melo (1897-1976), dentre outros (IPHAN, 2012).
} 


\section{A constituição política do Patrimônio Histórico Cultural brasileiro e a busca da formatação de uma identidade nacional}

Rahyan de Carvalho Alves; José Antônio Souza de Deus

conceber que a ruptura com o passado não fazia sentido para o nosso país [...] (NEVES; CARNEIRO, 2012, p.410).

Com esse movimento e com a busca por uma nova forma de se entender e projetar a nação brasileira, no ano de 1934 é criado o Ministério da Educação e Saúde (MES) que divulgou e controlou as atividades de pesquisas que pudessem trazer a construção simbólica das tradições e da cultura do passado do Brasil. E foi no âmbito das ações e propostas desenvolvidas por este ministério que os modernistas encontraram elementos decisivos para a consolidação do patrimônio histórico e nacional, figurando, então, como titular do MES, Gustavo Capanema (NEVES \& CARNEIRO, 2012).

A pedido de Gustavo Capanema Filho (1900-1985), é que o paulista Mário Raul Morais de Andrade (1893-1945), que na época era diretor do Departamento de Cultura da prefeitura de São Paulo, idealizou o anteprojeto relacionado à questão do patrimônio cultural por meio de suas pesquisas etnográficas e acesso a grandes literaturas. Projeto que, por sua vez, foi reformulado pelo mineiro Rodrigo Melo Franco de Andrade (1898-1969) e se tornou a Lei ${ }^{\circ}$. 378, promulgada em 13 de janeiro de 1937 (MEC/SPAHN/FNPM, 1980).

O anteprojeto tinha como objetivo a criação de um órgão responsável pela questão cultural no país, sendo encaminhado por Getúlio Dornelles Vargas (1882-1954), na época Presidente da República Federativa do Brasil, ao poder legislativo com o auxílio de intelectuais modernistas, como os poetas Manuel Carneiro de Souza Bandeira (1886-1968) e Carlos Drummond de Andrade (1902-1987) (SIMÃO, 2001; NUÑES, 2011).

Esta lei possibilitou que, entre os anos de 1936 para 1937, o governo criasse de forma experimental o SPHAN (Serviço do Patrimônio Histórico e Artístico Nacional), ampliando a visão do incipiente trabalho sobre o patrimônio nacional que se instalava, sendo "compreendida" a importância desse serviço, ao ponto de ser promulgado, em 30 de novembro de 1937, o Decreto-Lei de n ${ }^{\circ} .25$ que organiza a proteção do Patrimônio Histórico e Artístico Nacional (MEC/SPAHN/FNPM, 1980; SIMÃO, 2001; SILVA, 2003; KÖHLER, 2005; NUÑES, 2011).

Cabe, então, buscar entender que em 1937 o Brasil vivia o regime político do Estado Novo (1937-1945) com Vargas, que utilizou a representação do patriotismo como elemento crucial do imaginário político do país, vigorando em seu governo uma gestão centralizadora do poder e com um nacionalismo explícito para a aplicação de normas políticas e culturais, principalmente para os povos imigrantes. Dado que a entrada desses segmentos populacionais no Brasil estaria condicionada ao que esses poderiam realizar economicamente, em harmonia com a nova proposta social que estava nascendo, para que o governo pudesse construir uma 


\section{A constituição política do Patrimônio Histórico Cultural brasileiro e a busca da formatação de uma identidade nacional}

Rahyan de Carvalho Alves; José Antônio Souza de Deus

representação nacional, pois, para este governo a "grande lacuna" para o Brasil se afirmar como nação era a inexistência de uma cultura própria: de uma identidade.

A primeira relação que se pode fazer em busca de elementos históricos para a pretensão da emergência de um sentimento nacionalista é que, antes de qualquer coisa, o processo se deu “[...] voltado para a construção prática e simbólica de um espaço para a ideia de nação; como suporte para a formação do sentimento de pertencimento (nationness), e a construção histórica do Estado-nação sempre esteve associada ao nacionalismo como princípio ideológico" (LEITE, 2007, p.42, grifo do autor).

O Estado então define a partir do citado Decreto-lei promulgado, juntamente com o SPHAN, o Patrimônio Histórico e Artístico Nacional como sendo toda obra de arte pura e/ou aplicada aos saberes eruditos, nacional e ou estrangeiros. Definiu-se como obra de arte, reconhecida como o conjunto de bens móveis e imóveis do país, cuja conservação seja de interesse público e que tenha uma vinculação com fatos memoráveis da história da nação, integrando-se como instrumento legal no ato do tombamento ${ }^{4}$, cujo elemento é inscrito em um dos livros do SPHAN. Os critérios para tal definição estão quase sempre envolvidos na percepção do seu valor visual e arquitetônico, como os sítios urbanos coloniais e seus elementos de agregação - casarões, praças, chafarizes, dentre outros (MEC/SPAHN/FNPM, 1980; SIMÃO, 2001).

Como se pode perceber, a criação do SPHAN foi importante para a realização de projetos e vinculação de trabalhos para a projeção de novas formas de se compreender os elementos que cuja inserção fosse justificada como um bem cultural de âmbito nacional, além do seu tombamento. Todavia, o governo buscava, a princípio, inserir elementos que dessem suporte a um retrato social e histórico homogêneo que pudesse impulsionar a marca da cultura brasileira, mas marginalizando muitas manifestações populares o que divergia, assim, com os ideais de alguns membros, principalmente modernistas, que tinham como referência cultural toda relação de apropriação de sentimento de criação e forma de fazer através de um significado de interesse coletivo.

Para Nuñes (2011, p.43), é importante termos claro esses pontos de divergência, pois apesar de o governo buscar apoio técnico, intelectual, e até mesmo político, dos modernistas, no que se refere à cultura, “[...] o objetivo de ambos não se correspondiam, pois, os

\footnotetext{
${ }^{4}$ Inscrever um elemento no livro do tombo é inventariar e registrar um material para concretizar, legalmente, o seu valor cultural, social e humanitário. O conjunto urbanístico da cidade de Diamantina/MG, por exemplo, foi tombado no livro das Belas Artes, volume I. O tombo pode ser compreendido como agrupado ou separadamente. Torna-se interessante percebermos a inscrição agrupada, pois esta visa assegurar a paisagem num conjunto urbano, tentando evitar uma discriminação das áreas com imóveis semelhantes em valor cultural (SILVA, 2003).
} 


\section{A constituição política do Patrimônio Histórico Cultural brasileiro e a busca da formatação de uma identidade nacional}

Rahyan de Carvalho Alves; José Antônio Souza de Deus

modernistas buscavam não só o acesso como a valorização da cultura popular [...]", enquanto que na esfera política o que o governo pretendia, fundamentalmente, era criar uma cultura tradicional e de culto aos símbolos nacionais (como as bandeiras e os hinos) que deveriam ser reverenciados e respeitados pelas massas. Buscavam-se elementos que criassem referências:

[...] a todos que habitavam um mesmo território, unificando em torno de pretensos interesses e tradições comuns, resultando na imposição de uma língua nacional, de "costumes nacionais", de uma história nacional que se sobrepôs às memórias particulares e regionais. Enfim, o patrimônio passou a constituir uma coleção simbólica unificadora (RODIGUES, 2002, p.16).

$\mathrm{O}(\mathrm{s})$ patrimônio(s) culturais tornaram-se, nesse contexto, bases da política para a construção de um Estado nacional que utilizou narrativas memoriais, discursos que dão relevância à tradição para buscar uma afirmação de identidade coletiva. Gonçalves (2002, p.116) destaca que “[...] assim como no romance, o que está em foco nas narrativas de patrimônio é a experiência de formação de uma determinada subjetividade coletiva e, de certo modo, as narrativas de patrimônio são romances nacionais de formação".

Também se faz relevante entender que as políticas de patrimônio incorporam mais que uma pretensão ontológica para a vida coletiva, “[...] quando selecionam e destacam certos bens culturais que seriam representativos de uma tradição nacional capaz de manter vínculos comunitários da vida em sociedade" (LEITE, 2007, p.39). Elas buscam, também, uma experiência de vida que contemple a história de todos os sujeitos, mesmo que centrada em políticas culturais do Estado, articulando novas percepções dos espaços, experiências, concepções de vida e atores que marcaram a nação, numa tentativa de promover uma noção de nacionalidade que até então estava, e pode continuar difusa.

É relevante assinalar que o mecenato cultural que o Estado buscava, na gestão de Capanema, se deve muito a atuação do MES, conforme destaca Köhler (2005), uma vez que as ações de glorificação da memória nacional influenciaram a formação do atual Instituto do Patrimônio Histórico Artístico Nacional. Para o autor, a ação do MES, no período Vargas, foi um marco que destacou a constituição da cultura e do patrimônio, principalmente, por três características que apresentamos a seguir.

A primeira foi, como já mencionamos, a criação de um órgão (SPHAN) com o objetivo explícito de salvaguardar o patrimônio histórico e artístico nacional. A segunda caracteriza-se pela defesa da cultura e da nacionalidade brasileira se concretizar por lei específica. E a terceira, foi uma ação cultural nitidamente direcionada à afirmação do catolicismo tradicional como religião nacional, aliada ao culto aos símbolos e aos vultos históricos mitificados, “[...] bem como a proteção aos monumentos históricos e artísticos nacionais, em detrimento das manifestações populares" (KÖHLER, 2005, p.30). 


\section{A constituição política do Patrimônio Histórico Cultural brasileiro e a busca da formatação de uma identidade nacional}

Rahyan de Carvalho Alves; José Antônio Souza de Deus

A última questão citada corresponde a um dos desafios que o Brasil começa a enfrentar nos últimos anos: a inserção e o tombamento dos elementos que traduzem a cultura das minorias étnicas. Pois, conforme Leite (2007, pp.51-52) aponta, a política dos tombamentos que marcam a história da "[...] preservação do patrimônio cultural do Brasil, entre 1938 e 1981, refere-se à etnia branca, ao catolicismo, às classes dominantes e às edificações-símbolo do poder estatal" apenas.

O conceito de patrimônio e do bem cultural é um valor que iria nortear as práticas culturais no Brasil nos anos seguinte, envolvendo todas as forças possíveis para a promoção de um sentimento a partir dos tombos, como foi imposto pelo Estado Novo. Utilizando a arquitetura como elemento fundamental para caracterizar e identificar o homem com o lugar e a nação, quando, priorizou-se, assim, o patrimônio edificado e arquitetônico, a chamada "pedra e cal" (FERNANDES, 2012). Mas o Estado foi puramente seletivo "[...] ao atentar para fatos (construções, ruas e monumentos) que são conservados como um registro do tempo que está cheio de brechas" (TUAN, 2011, p.16).

Uma crítica que se pode fazer ao conceito de patrimônio histórico e artístico nacional firmado no Estado Novo é que, infelizmente, ele não conseguiu reconhecer a diversidade cultural, ao fazer uma seleção restrita de aspectos da história e da arquitetura nacional. Nessa perspectiva é que foram focalizados "[...] os monumentos de pedra e cal representativos da etnia branca e de sua elite militar, eclesiástica e civil, com a marginalização das manifestações populares, do legado das etnias negra e indígena" (KÖHLER, 2005, p.32).

O projeto elaborado por Mário de Andrade propugnava uma preservação mais ampla da cultura e memória do país, mas a política de preservação do SPHAN inclinou-se, focalmente, para "[...] a restauração arquitetônica de cunho "fachadista" dos bens imóveis de pedra e cal, cujos monumentos (em sua maioria, representativos do estilo barroco colonial mineiro) expressavam uma versão oficial do patrimônio" (LEITE, 2007, p.50, grifo do autor) que se queria expressar.

Envolvidos no projeto de buscar as raízes e a identidade nacional, “[...] os modernistas voltam-se para o interior do Brasil, mais precisamente para as cidades coloniais de Minas Gerais cuja arquitetura barroca ${ }^{5}$ expressa o retorno a um passado, tipo como legítimo, e

\footnotetext{
${ }^{5}$ A manifestação da arte barroca, termo que significa "pérola irregular ou imperfeita", se iniciou na Itália, no século XVI e XVII, estendendo para o nosso continente durante os séculos XVII e XVIII, utilizada como instrumento de afirmação da fé cristã no movimento da Contra-Reforma, proveniente do alastramento do protestantismo. E diretamente, a arquitetura barroca no Brasil é projetada desde a colonização portuguesa, introduzida por missionários católicos, tendo ao longo do período colonial a Igreja e os poderes da colônia como os gestores de palácios e patrocinadores das artes, a fim de promover um processo de assimilação religiosa aos povos que aqui se encontravam, deixando um legado de elementos da arte sacra. E com a descoberta do Ouro no
} 


\title{
A constituição política do Patrimônio Histórico Cultural brasileiro e a busca da formatação de uma identidade nacional
}

\author{
Rahyan de Carvalho Alves; José Antônio Souza de Deus
}

representativo da originalidade da cultura brasileira" (LEITE, 2007, p.49, grifo nosso). Foi nas cidades antigas das Minas que eles encontraram "[...] aquilo que procuravam; monumentos e núcleos urbanos coloniais abandonados, mas que tinham sua integridade estilística original, que contavam a história e refletiam a tradução almejada" (SIMÃO, 2001, p.28). A relação dos intelectuais do SPHAN e dos modernistas com Minas Gerais, deve-se então:

[...] basicamente à busca dessa expressão tradicional da cultural. Minas já era considerada um polo catalisador de ideias. As diferentes viagens que muitos intelectuais fizeram ao interior do estado, dentre eles o próprio Mário de Andrade, o arquiteto Lúcio Costa e o jornalista Rodrigo Melo Franco - o primeiro diretor do SPHAN -, foram marcos desse "redescobrimento" do Brasil e de suas expressões culturais consideradas genuinamente nacionais (LEITE, 2007, p.50).

As Minas do século XVIII eram, aliás, percebidas como o foco da civilização do passado brasileiro, uma vez que se remetia nos traçados de suas casas, ruas, vielas e praças a fixação do "[...] homem que havia se materializado, a economia do ouro que tinha alcançado importância internacional e a vida urbana que se traduzia em civilidade e ambiente propício ao cultivo das artes e da cultura" (JULIÃO, 2009, pp.149-150). O Estado de Minas Gerais foi assim alvo de ações preservacionistas por seu acervo monumental arquitetônico, pois ali se encontrava vestígios do ambiente urbano, da atividade mineradora, das formas de trabalho, dos rituais religiosos, dos modos de viver e ser, da vida pública e privada, promovendo justificativas para inclusão de elementos em tombos e para a criação de museus.

Como aponta Julião (2009), superintendente de museus do estado de Minas Gerais, grandes iniciativas foram realizadas pelo SPHAN entre as décadas de 1930 e 1950, como os serviços museológicos que se localizaram entre os Estados do Rio Grande do Sul, Santa Catarina, Goiás, Pernambuco e, sobretudo, Minas Gerais. Mas, foi este último Estado o mais beneficiado nesta jornada museológica, em que se propiciou assinalar, assim como o fizera com os bens arquitetônicos, o caráter singular do patrimônio móvel mineiro, cujo valor superava os interesses regionais, merecendo, portanto a proteção nacional.

Este foco dado a Minas Gerais se deve à preservação da herança cultural no Estado, a qual se remete à atividade da extração do ouro, dos diamantes, cenário dos garimpos, movimentos sociais de independência, como a Inconfidência Mineira (1789), e toda a complexidade da vida em sociedade desenvolvida nos séculos XVIII e XIX. Essas

país, em especial no Estado que hoje conhecemos como Minas Gerais, começa a estender o uso da arte barroca, pois a distância do litoral e as dificuldades de importação de materiais e técnicas construtivas para tal arte vão dar ao barroco de Minas Gerais uma característica marcada pelo regionalismo. Isso é constatado, principalmente, em sua arquitetura que é derivada de grande complexidade na construção do espaço interno e pela busca de efeitos impactantes, e teatrais, na integração da pintura e escultura, com uma arquitetura decorativa, tendo uma preferência por plantas axiais ou centralizadas, com uso de contrastes entre cheios e vazios, entre formas convexas e côncavas e pela exploração de efeitos de luz e sombra (IPHAN, 2012). 


\section{A constituição política do Patrimônio Histórico Cultural brasileiro e a busca da formatação de uma identidade nacional}

Rahyan de Carvalho Alves; José Antônio Souza de Deus

características serviam para objetivar e potencializar, conforme aborda Julião (2009), uma matriz histórico-social cujo enredo, evocado por meio do repertório fixo de objetos, traduz uma imagem idealizada da sociedade, na qual predominam a herança da cultura barroca, católica e de um universo estético erudito materialmente requintado.

Então, desde objetos mais pessoais até monumentos urbanos, os profissionais do SPHAN faziam (e ainda fazem) pesquisas e diagnósticos à procura de histórias do povo brasileiro, mas, neste momento, o órgão tinha como emblema postular uma Civilização do Ouro, tendo como referencial a história colonial e a supremacia da Igreja, pois esta última detinha, no período, o papel principal em atos festivos, cerimoniais, além de ter sido uma grande patrocinadora da arte. Entre os objetos que os artistas e técnicos da época descreveram, destacam-se as:

[...] cadeirinhas de arruar, luminárias, fragmentos construtivos, instrumentos de trabalho como os de mineração, armas, acessórios de montaria, instrumentos musicais, tinteiros e penas de escrever, marcos de vilas. Entre as categorias de objetos, aquelas ligadas à vida religiosa e à Igreja predominavam nas coleções, as quais abarcavam desde objetos processionais e litúrgicos, incluindo prataria, paramentos e alfaias, até o mobiliário integrado à arquitetura religiosa, a exemplo de retábulos e das pias batismais (JULIÃO, 2009, p.152).

Essa construção da imagem de Minas Gerais iria resgatar uma memória coletiva nacional e, aos poucos, promoveria “[...] uma apropriação do passado que pudesse ser lembrado pela população do país" (NEVES \& CARNEIRO, 2012, p.410). Tanto que, por mais de 30 anos, a atuação do SPHAN promoveu em Minas Gerais o espírito de nacionalidade brasileira, pela sua civilização mineradora e pela arte do período "oitocentista" que constituíram marcas históricas que produziram um patrimônio capaz de operar uma identidade e colocar o país entre as nações “cultas", em especial pela consagração do barroco (JULIÃO, 2009).

Nesse contexto, algumas cidades no país, no ano de 1938, tiveram alguns edifícios e monumentos “[...] selecionados para tombamento em função de sua capacidade de expressar de forma modelar - a história oficial como suposta síntese da memória, tradição e identidade nacional" (LEITE, 2007, p.51), como nos casos de Mariana (1696), Serro (1701), Ouro Preto (1711), São João Del-Rei (1713), Tiradentes (1718) e Diamantina (1832), todas cidades mineiras. Em 1946, o SPHAN passa a denominar-se Departamento do Patrimônio Histórico e Artístico Nacional (DRPHAN), fornecendo novos serviços (IPHAN, 2012).

O novo órgão DRPHAN preservou inúmeros elementos imóveis, em especial, as belas Igrejas Barrocas, os imponentes Fortes Militares, as Casas-Grandes e os Sobrados Coloniais, 


\section{A constituição política do Patrimônio Histórico Cultural brasileiro e a busca da formatação de uma identidade nacional}

Rahyan de Carvalho Alves; José Antônio Souza de Deus

mas também esqueceu muitas histórias e feitos do passado, como as "Senzalas, os Quilombos, as Vilas Operárias e os Cortiços (...), consagrando, portanto, uma memória nacional vinculada apenas a determinados segmentos da sociedade e a um estilo arquitetônico" (FERNANDES, 2012, p.13). Mas, “[...] não podemos descartar, “a priori”, a eficácia simbólica que os significados sociais do patrimônio cultural tiveram e continuam a ter na construção social dos lugares e das pessoas" (LEITE, 2007, p. 40, grifo do autor), pois essa foi uma tentativa de resgate da memória de um país que estava se encontrando e tentando se afirmar.

Para se ter a dimensão da atividade assumida por este novo serviço cultural que se instalava do país, os trinta anos da gestão Rodrigo Melo Franco de Andrade resultaram os estudos do(s) patrimônio(s), de sua defesa, do tombamento e da proteção por leis federais (totalizando cerca de 716 monumentos e obras, 28 conjuntos arquitetônicos parciais e 12 conjuntos arquitetônicos de cidades reconhecidas). Foram patrocinadas pesquisas, decifrações e restaurações de documentos de arquivos civis e eclesiásticos de vários Estados, propondo-se até à elevação de categoria de monumento nacional de cidades como: Parati (RJ) e Mariana (MG); e a criação e fomento de novos museus, a exemplo dos regionais do Diamante (Diamantina, MG), da Inconfidência (Ouro Preto, MG) e o da Imigração e Colonização (Joinville, SC) (KÖHLER, 2005).

Em meados dos anos 60 (século XX), a política do reconhecimento e preservação do(s) patrimônio(s) transformou-se em preocupação urgente, pois o desenvolvimento econômico que se instalava no país contribuiu, significativamente, para a intensificação do desaparecimento de obras arquitetônicas que poderiam ser consideradas históricas. Nesse contexto, Neves \& Carneiro (2012, pp.416-417) destacam que os grupos sociais hegemônicos potencializavam uma nova forma de se perceber a vida urbana, em que a modernidade era associada à ideia de se "[...] construir edificações modernas e o país deveria se industrializar em ritmo acelerado, o que favorecia, em paralelo, a indiferença em relação aos edifícios que representavam algo do passado". Acentuado pelos processos de abertura e asfaltamento de estradas e pelos pequenos, mas promissores, movimentos turísticos que algumas cidades estavam a receber (SIMÃO, 2001).

Nessa conjuntura particular que o DRPHAN, agora com a gestão de Renato de Azevedo Duarte Soeiro (1911-1984), tentou mediar a relação entre a preservação da tradição (patrimônios) e da projeção da modernidade (intervenções urbanísticas), principalmente articulando a questão patrimonial ao desenvolvimento econômico que o Brasil almejava alcançar a partir da inserção de uma política patrimonial nos parâmetros adotados pelos 


\section{A constituição política do Patrimônio Histórico Cultural brasileiro e a busca da formatação de uma identidade nacional}

Rahyan de Carvalho Alves; José Antônio Souza de Deus

órgãos internacionais, com destaque para as recomendações da UNESCO e os parâmetros das Cartas de Atenas e Veneza (IPHAN, 2012).

As populações das cidades que detêm o reconhecimento de elementos como patrimônio histórico cultural, oficialmente tombado e reconhecido pelo órgão responsável na época, “[...] sentem-se lesadas pelas restrições impostas ao uso de suas propriedades, em conformidade com o costume brasileiro" (SIMÃO, 2001, pp.42-43). Além dos grandes problemas enfrentados pelos moradores, como a deficiência na infraestrutura urbanística no que se refere aos serviços de captação, tratamento e distribuição de água (resultado da dificuldade em inserir aparelhos urbanísticos respeitando os elementos tombados), dentre outros. Havia, ainda, a escassez no que se refere a serviços e, com isso, a estagnação do comércio e da vida nas cidades, além de projetar um crescimento urbano desordenado com poucas alternativas de lazer.

E em função de todos estes fatores aludidos, os moradores das cidades tombadas convivem diariamente com o ônus da preservação. Pode ser observado, neste sentido, um sentimento ambíguo em relação ao patrimônio, pois ao mesmo tempo em que ele remete ao passado, ele "[...] indica impossibilidade de mudanças e, consequentemente, de progresso [...]” (SIMÃO, 2001, p.44). Progresso que estes moradores desejavam e ainda desejam, não apenas promovido pela corrente do processo de preservar sem considerar a vida ativa na cidade. A importância maior atribuída a esta relação de preservação e a continuação das atividades diárias se impregna nos valores que os elementos do passado precisam estar amplamente divulgados, mas também devidamente relativizados. Contextualizados na realidade concreta da cidade e dos seus habitantes.

Importante frisar que neste momento o processo de requerer o tombamento de um bem - fosse ele individual ou de conjunto - não pressupunha o aval da população ou dos interessados diretamente pelo bem (SIMÃO, 2001; SILVA, 2003), diferentemente de hoje, o que promovia uma imposição sobre a cidade e a vida de seus habitantes.

Além destas imposições, existia, e existe, a restrição colocada para a população no sentido de impedir modificações das paisagens onde se tem bens tombados, o que é descrito no artigo 18 do Decreto-Lei $n^{\circ}$. 25/37, que destaca que sem a devida autorização dos órgãos competentes não se pode fazer construções que impeçam ou reduzam a visibilidade do elemento, ações como: corte de árvores descaracterizando o cenário do local, novas construções no interior dos imóveis, fixação de cartazes de publicidade em paredes de casarões, instalações de cabos elétricos e de antenas de televisão que dificultem a visualização do patrimônio, dentre outros, ficando, portanto, ao proprietário a obrigação de conservar o 


\section{A constituição política do Patrimônio Histórico Cultural brasileiro e a busca da formatação de uma identidade nacional}

Rahyan de Carvalho Alves; José Antônio Souza de Deus

bem tombado e podendo, ele, em caso contrário, ser multado (SILVA, 2003; CERQUEIRA, 2006).

Em $1970^{6}$ o DPHAN se transforma em IPHAN. E este último se estende em: SPHAN, restaurando o órgão normativo e, Fundação Nacional pró-Memória (FNPM), órgão executivo, idealizado para promover estratégias para resolver a carência financeira do instituto, dada “[...] a impossibilidade de o IPHAN manter-se com recurso do governo federal” (LEITE, 2007, p.53); aliado à urgência que as cidades com arsenal patrimonial estavam passando no que se refere à dinâmica econômica, percebendo a necessidade de encarar tais centros urbanos como detentores de um acervo cultural que necessita ser percebido como um conjunto de organismo dinâmico, em constante mudança, devido à busca pelo crescimento financeiro dos moradores.

Especialmente porque muitos destes dependem de seus estabelecimentos comerciais ou outras atividades direcionadas à cidade. E congregado à Superintendência para o Desenvolvimento do Nordeste (SUDENE), mais à Empresa Brasileira de Turismo (EMBRATUR) e o Serviço do Patrimônio Histórico e Artístico Nacional (SPHAN), o IPHAN percebe o turismo ${ }^{7}$ como um setor para ativar o comércio nas cidades com bens tombados pelo governo (SIMÃO, 2001).

Em 1973, surge, também, o Programa Integrado de Reconstrução das Cidades Históricas $(\mathrm{PCH})$ que juntou forças com os órgãos anteriormente citados para recuperar economicamente as cidades. Inicialmente do Nordeste do país, tentando promover uma integração da riqueza patrimonial através do turismo, potencializando os conjuntos urbanos que foram considerados patrimônios históricos nacionais. Em 1976, o PCH se expandiu para os Estados do Espírito Santo e Rio de Janeiro, e, em 1977, para todo o país; todavia, como Neves \& Carneiro (2012, pp.417-418) destacam, “[...] algumas cidades históricas do estado de Minas Gerais não receberam recursos do $\mathrm{PCH}$ e as primeiras ações para esta natureza apareceram como iniciativas de instituições civis". Nesse contexto:

$\mathrm{O}$ PCH tinha como principal objetivo o desenvolvimento econômico e social de localidades pobres do país, que, em geral, tinham grande parte do seu patrimônio preservado em virtude da estagnação econômica pela qual tinham passado. Ao invés de recuperar bens levando-se em conta apenas o valor histórico e artístico dos

\footnotetext{
${ }^{6}$ Em Minas Gerais, em 1971, foi criado um órgão responsável pela preservação do patrimônio, o Instituto Estadual do Patrimônio Histórico e Artístico de Minas Gerais (IEPHA), que possui relativa autonomia administrativa, financeira e mecanismos legais para realizar os processo de tombamentos no nível estadual (IPHAN, 2012).

${ }^{7}$ O professor Everaldo Batista da Costa (2009, p.14) aponta, em seus estudos, que Diamantina/MG tem a valorização simbólica e econômica dos seus bens culturais destacado nitidamente no " [...] barroco como um elemento diferencial sobre o qual se projeta o valor de mercado no contexto turístico".
} 


\section{A constituição política do Patrimônio Histórico Cultural brasileiro e a busca da formatação de uma identidade nacional}

Rahyan de Carvalho Alves; José Antônio Souza de Deus

mesmos, o PCH considerava o potencial turístico de conjuntos e monumentos [...] (KÖHLER, 2005, p.39).

Entre 1970 e 1980 a preservação dos patrimônios arqueológico, natural e arquitetônico histórico também passou a fazer parte de uma política relacionada a uma nova concepção de identidade nacional e ao desenvolvimento econômico cultural e turístico do país. Ou seja, instala-se, então, a atividade turística com o objetivo de dinamizar as atividades econômicas locais, além de promover um intercâmbio cultural com proposta de utilizar tal atividade como ferramenta pedagógica dos patrimônios disponível para "todos" os cidadãos (LONDRES, 2000; NUÑES, 2011).

\section{Nuances da compreensão dos elementos que representam a identidade do povo brasileiro e seus signos}

Neste processo em curso de reconhecimento, valorização do patrimônio e com a proposta de investir nos elementos-símbolos para a afirmação de uma sociedade e para dinamizar o mercado financeiro, através do turismo, os órgãos do governo, como o IPHAN, percebeu que os elementos patrimoniais culturais brasileiros extrapolavam as características do barroco e os elementos arquitetônicos do período colonial. A diversidade do povo brasileiro passou, nesse contexto, a também ser reconhecida como representativa da memória da nação. Então, pode-se dizer que entre 1970 e 1980, iniciou-se o processo de redemocratização do IPHAN, que até então apenas se preocupava com os sítios históricos e a identidade arquitetônica, ocorrendo um movimento intenso e crítico em direção à conceituação do que seja o patrimônio, principalmente vinculado ao turismo.

Entendia-se que o patrimônio cultural brasileiro não devia se restringir aos grandes monumentos, aos testemunhos da história "oficial", em que, sobretudo as elites se reconhecem, mas devia incluir também manifestações culturais representativas para os outros grupos que compõem a sociedade brasileira - os índios, os negros, os imigrantes, as classes populares em geral [...] (LONDRES, 2000, p.11).

Nesse sentido, a política patrimonial modifica-se na concepção de perceber a diversidade das ações, manifestações e crenças sociais que completam a unidade do nosso território. Ficando claro que este novo olhar que o país deposita em suas ações patrimoniais avança, pois a própria Constituição ${ }^{8}$ Federal Brasileira de 1988 destina, no seu capítulo III,

\footnotetext{
${ }^{8}$ Silva (2003) destaca que as Constituições brasileiras, tanto a de 1824 como a de 1891 , eram omissas quanto à proteção do que conhecemos hoje como bens culturais. A primeira referência que encontramos a estes está atrelada à Constituição de 1934, em que se destaca o papel da União em proteger as belezas naturais e os monumentos históricos ou artísticos, impedindo a evasão das obras de artes reconhecidas para outros países e penalizando as quem destruir. A partir daí, as demais constituições percebem e reconhecem a necessidade de proteger os patrimônios, como em 1937 e a de 1946 quando reforçam a importância do patrimônio nacional e se reconhece que toda ação contra ele é um atentado a história da nação. E por fim, a Constituição de 1988 oferece
} 


\section{A constituição política do Patrimônio Histórico Cultural brasileiro e a busca da formatação de uma identidade nacional}

Rahyan de Carvalho Alves; José Antônio Souza de Deus

Da Educação, da Cultura e do Desporto, em sua seção II, novas disposições específicas sobre o patrimônio cultural. Figurando como novas disposições de temas, atreladas ao reconhecimento Constitucional do patrimônio cultural nacional:

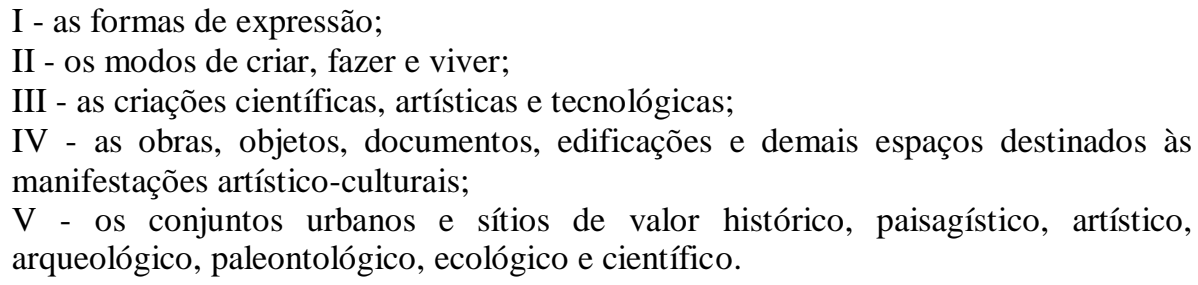

Outros avanços sobre os rumos políticos do patrimônio foram percebidos entre 1990 e 2000, pois os Estados se empenharam em contribuir e promover o reconhecimento e a manutenção dos seus bens tombados. Além de perpetuar a memória da pátria, por meio destes bens, ocorrem também atividades comerciais advindas do turismo, sobretudo, o cultural. Assim o Estado de Minas Gerais promoveu um grande passo para a continuidade dos serviços do patrimônio ao criar a Lei $\mathrm{n}^{\circ}$. 12.040/95, que estabeleceu novos critérios para que o repasse do capital arrecadado pelo imposto sobre operações relativas à circulação de mercadorias e sobre prestações de serviços de transporte interestadual, intermunicipal e de comunicação (ICMS) fosse aplicado em ações políticas culturais, sobretudo o tombamento (IPHAN, 2012).

Ocorreram mais progressos sobre o entendimento do que seja o patrimônio cultural no país, uma vez que a concepção sobre a genialidade do fazer humano extrapolou a valorização, tão somente, dos elementos materiais. O exemplo mais claro disso pode ser apontado em 1997, quando o IPHAN promoveu em Fortaleza (CE) seminário internacional para discutir a importância e o significado do patrimônio imaterial. Essa discussão se iniciou em 1975, mas adquiriu força no final da década de 1990, tendo como elemento da experiência desses patrimônios as cidades de Goiás (GO) e Porto Seguro (BA). Esse seminário promoveu o “[...] Inventário Nacional de Referências Culturais (INRC), que teve como objetivo identificar, documentar e registrar os bens culturais expressivos da diversidade cultural brasileira" (NETO, 2000, p.23, grifo do autor).

Tal atividade destaca a projeção do Patrimônio Imaterial no Brasil, reconhecido pelo Ministério da Cultura, acumulando novos símbolos culturais através dos levantamentos realizados em “[...] núcleo histórico, como a do Serro (MG), em 1995; em Diamantina (MG) e Goiás (GO); em 1998” (NETO, 2000, p.23). Mas, não se pode esquecer de que o patrimônio imaterial já configurava nas preocupações de Mário de Andrade, no início da construção do seu

maior clareza no sentido da representação e preservação dos elementos tombados, juntamente com a relevância de perpetuarmos os bens, em suas naturezas, para as futuras gerações. Além de ser "[...] nesta Constituição a primeira vez que a noção de cultura é homologada a de patrimônio” (PEREIRA, 2008, p.11). 


\section{A constituição política do Patrimônio Histórico Cultural brasileiro e a busca da formatação de uma identidade nacional}

Rahyan de Carvalho Alves; José Antônio Souza de Deus

anteprojeto, todavia, a busca da identidade nacional, direcionada pelo Estado Novo, limitou-se a dar ênfase aos sítios arquitetônicos.

De acordo com Neto (2000, p.24, grifo do autor), o Patrimônio Imaterial no Brasil tem como norteadores os:

1. Saberes e modos de fazer enraizados no cotidiano das comunidades;

2. Celebrações, festas e folguedos que marcam espiritualmente a vivência do trabalho, da religiosidade, do entretenimento e da vida cotidiana;

3. Linguagens musicais, iconográficas e performáticas;

4. Espaços em que se produzem as práticas culturais [...].

Nesse sentido, instituiu-se, por meio do Decreto de Lei $\mathrm{n}^{\circ}$. 3.551, de agosto de 2000, o registro do patrimônio imaterial como instrumento legal de preservação, criando-se, ainda, o registro de bem de natureza imaterial em livros, que Nuñes (2011) destaca como sendo: o ( $i$ ) Livro de Registro dos Saberes: para a inscrição de conhecimentos e modos de fazer, enraizados no cotidiano das comunidades; o (ii) Livro de Registro das Celebrações: para rituais e festas que marcam a vivência coletiva; o (iii) Livro de Registro das Formas de Expressão: para o registro das manifestações literárias, musicais, plásticas, cênicas e lúdicas e; o (iv) Livro de Registro dos Lugares: para destacar as belezas e relevância de cidades reconhecidas como excepcional.

Como exemplos desta valorização do patrimônio imaterial no Brasil, o esporte, a dança e a manifestação artística da capoeira, herança deixada pelos escravos africanos (por muito tempo proibido pelo código penal brasileiro, descrito no Decreto $\mathrm{n}^{\circ}$. 847, de 11 de outubro de 1890), foi reconhecido, no ano de 2008, como Patrimônio Cultural Imaterial do país. Juntamente com as expressões orais e gráficas dos índios “Wajãpis”, do Amapá e o samba de roda do Recôncavo Baiano (NETO, 2000).

Para consolidar essa forma de se compreender a cultura patrimonial no Brasil e congregar os bens materiais e imateriais, o Antropólogo Antônio Augusto Arantes Neto (1944), presidente do IPHAN entre os anos de 2004 e 2006, implantou o Departamento de Patrimônio Imaterial e o Programa Nacional do Patrimônio Imaterial no Instituto do Patrimônio Histórico Artístico Nacional (IPHAN, 2012).

Com todas essas convenções e interpretações, e no sentido de se compreender a constituição do patrimônio cultural no Brasil, pode-se refletir como a memória e a identidade cultural se constituem como alvos que se atingem, cada vez mais, em uma democracia cultural no tocante à valorização de todas as formas e expressões que o ser humano cria e reinventa em seu lugar ou em seu imaginário, firmando o sentido do patrimônio na sociedade.

\section{Considerações finais}


A constituição política do Patrimônio Histórico Cultural brasileiro e a busca da formatação de uma identidade nacional

Rahyan de Carvalho Alves; José Antônio Souza de Deus

O patrimônio histórico cultural é, sem dúvida, uma referência histórica que promove bases para os elementos sobre os quais se podem depositar as lembranças. E ultrapassa as marcas de afirmação de uma identidade, como ocorreu e ocorre no Brasil. A importância do patrimônio é, sobretudo percebida ao rastrearmos “[...] os espaços lisos da cidade, pois ao selecionar bens culturais representativos da memória das tradições da nação, relaciona-se a possibilidade de fixar pontos que orientam itinerários, demarcam trajetórias e criam lugares" (LEITE, 2007, p.40, grifo do autor). Esses lugares passam a constituir os nossos norteadores históricos, de orgulho, de satisfação ou até mesmo de indagação das pessoas, políticas etc.

Os lugares que são criados e recriados pela presença do patrimônio têm como apresentação a referência da experiência social do indivíduo, representando diversos grupos e categorias sociais. Tornam-se elementos-simbólicos que começam a narrar a representatividade social, passando de uma totalidade homogênea para a heterogeneidade do reconhecimento de "todos" na sociedade (GONÇALVES, 2002). Dessa forma, o sentido de pertencimento ao lugar vai se apropriando do patrimônio e este vai se transmutando na vivência do homem, sendo assim, a política do reconhecimento do patrimônio histórico no Brasil é rico, diverso e deve, sempre, ser legitimo vindo do povo e para o povo, ao ponto de que os “[...] cidadãos de uma possível identificação sociocultural ao local, e permitindo que se aproprie dos bens" (SIMÃO, 2001, p.93).

\section{REFERÊNCIAS}

COSTA, Everaldo Batista da. A dialética da construção destrutiva na consagração do Patrimônio Mundial. São Paulo (SP): Humanitas: FAPESP, 2009. 308p.

FERNANDES, José Ricardo Oriá. Muito antes do SPHAN: A política do patrimônio histórico no Brasil. Disponível em: http://culturadig/politicaculturalcasaderuibaret>. Acesso em: 12 jan. 2020.

GONÇALVES, José Reginaldo Santos. Monumentalidade e cotidiano: os patrimônios culturais como gênero de discurso. In.: OLIVEIRA, Lúcia Lippi (Org.). Cidade: história e desafios. Rio de Janeiro (RJ): Fundação Getulio Vargas, 2002. p.108-123.

IPHAN. A Igreja de São Francisco de Assis em Diamantina. Ministério da Cultura. Instituto do Patrimônio Histórico Artístico Nacional. Brasília (DF), 2009. 335p.

IPHAN.. Comitê técnico da candidatura do Rio à Patrimônio Mundial. Ministério das Relações Exteriores. Ministério da Cultura. Instituto do Patrimônio Histórico Artístico Nacional. Brasília (DF), 2012. 11p.

JULIÃO, Letícia. O Sphan e a cultura museológica no Brasil. Estudos Históricos, Rio de Janeiro (RJ), v.22, n.43, p.141-161, jan./jun. 2009. 
A constituição política do Patrimônio Histórico Cultural brasileiro e a busca da formatação de uma identidade nacional

Rahyan de Carvalho Alves; José Antônio Souza de Deus

KÖHLER, André Fontan. Antes que Caia! Patrimônio histórico e turismo em Igarassu, Pernambuco. 397f. Dissertação (Mestrado). Fundação Getulio Vargas - Escola de Administração de Empresas de São Paulo, São Paulo (SP), 2005.

LEITE, Rogério Proença. Contra-usos da cidade: lugares e espaços públicos na experiência urbana contemporânea. $2^{\text {a }}$ Edição. Campinas (SP): EdUNICAMP \& EdUFS, 2007. 326p.

LONDRES, Cecília. Referências culturais: base para novas políticas de patrimônio. In.: CORSINO, Célia Maria \& NETO, Antônio Augusto Arantes (Orgs.). Inventário nacional de referências culturais: manual de aplicação. Brasília (DF): Instituto do Patrimônio Histórico e Artístico Nacional, 2000. p.11-21.

MEC/SPHAN/FNPM. Proteção e revitalização do patrimônio cultural no Brasil: uma trajetória. Brasília: SPHAN/FNPM, 1980. p.01-26.

NETO, Antônio Augusto Arantes. Introdução a bens. In.: CORSINO, Célia Maria \& NETO, Antônio Augusto Arantes (Orgs.). Inventário nacional de referências culturais: manual de aplicação. Brasília (DF): Instituto do Patrimônio Histórico e Artístico Nacional, 2000. p.2325 .

NEVES, Rodrigo \& CARNEIRO, Eder Jurandir. Imagens do patrimônio e turismo: metarmofoses e "mercadorização" do território central de Tiradentes, Minas Gerais. Espaço \& Geografia, Brasília (DF), v.15, n.2, pp.407-441, 2012.

NUÑES, Déborah Coimba. Educação patrimonial nos bastidores do processo. A formação dos agentes multiplicadores e as metodologias de ensino aplicadas na apreensão de bens culturais: o caso de São João Del-Rei/Minas Gerais. 95f. Dissertação (Mestrado) Programa de Pós-graduação em Memória Social e Patrimônio Cultural - Universidade Federal de Pelotas, Pelotas (RS), 2011.

PEREIRA, Júlio César. O conceito de cultura na Constituição Federal de 1988. In.: V Encontro de Estudos Multidisciplinares em Cultura. Universidade Federal da Bahia, Faculdade de Comunicação, Salvador (BA). [Anais...] 2008. p.01-14.

RODRIGUES, Marly. Preservar e consumir: o patrimônio histórico e o turismo. In.: FUNARI, Pedro Paulo \& PINSKY, Jaime. Turismo e patrimônio cultural. $2^{\text {a }}$ Edição. São Paulo (SP): Contexto, 2002. p.15-24.

SILVA, Fernando Fernandes da. As cidades brasileiras e o Patrimônio Cultural da Humanidade. São Paulo (SP): EdUSP, 2003. 204p.

SIMÃO, Maria Cristina Rocha. Preservação do patrimônio cultural em cidades. Belo Horizonte (MG): Autêntica, 2001. 102p.

TUAN, Yi-Fu. Espaço, tempo, lugar: um arcabouço humanista. Tradução de Werther Holzer. Geograficidade v.01, n.01, inverno, 2011. p.08-19. 